\title{
3 Thermal curing of an epoxy-anhydride system modified 4 with hyperbranched poly(ethylene imine)s with different 5 terminal groups
}

6 J. M. Morancho' ${ }^{1}$ (D) X. Fernández-Francos ${ }^{1} \cdot$ C. $_{\text {Acebo }}^{2} \cdot$ X. Ramis ${ }^{1}$.

7 J. M. Salla ${ }^{1} \cdot \grave{\text { À. Serra }}{ }^{2}$

8 Received: 26 October 2015/ Accepted: 25 February 2016

9 (C) Akadémiai Kiadó, Budapest, Hungary 2016

A1

A6

\begin{abstract}
New hyperbranched polymers (HBP) have been synthesized by reaction of a poly(ethylene imine) with phenyl and $t$-butyl isocyanates. These HBPs have been characterized by ${ }^{1} \mathrm{H}-\mathrm{NMR}$ (nuclear magnetic resonance of hydrogen) and Fourier transform infrared spectroscopy. Their influence on the curing and properties of epoxy-anhydride thermosets has been studied by different techniques: differential scanning calorimetry (DSC), dynamic mechanical analysis (DMA), and thermogravimetry (TG). The curing kinetics has been studied with DSC. Integral isoconversional method and the Šesták-Berggren model have been used to determine the activation energy and the frequency factor. The kinetic parameters are very similar for all the studied systems at the middle stage of the process, but changes are observed at the beginning and at the end of the process when these modifiers are used. The HBPs reduce the glass transition temperature of the cured materials. In addition, from the DMA analysis it can be seen that the HBP modifier obtained from phenyl isocyanate hardly changes the storage modulus, but the obtained ones from $t$-butyl isocyanate decrease it. TG analysis reveals a decrease in the onset temperature of the degradation process upon addition of the HBPs.
\end{abstract}

\section{J. M. Morancho}

morancho@mmt.upc.edu

1 Thermodynamics Laboratory, Heat Engines Department, ETSEIB, Universitat Politècnica de Catalunya, Av. Diagonal 647, 08028 Barcelona, Spain

2 Department of Analytical and Organic Chemistry, Universitat Rovira i Virgili, C/Marcel-lí Domingo s/n, 43007 Tarragona, Spain
Keywords Epoxy networks - Thermal curing · Hyperbranched polymers $\cdot$ Kinetics

\section{Introduction}

Epoxy resins are widely used in applications such as adhesives, coatings, electric laminates, encapsulation of semiconductor devices, matrix material for composites, structural components [1-12], and cryogenic engineering [13-15] because of their mechanical properties, adhesion, and chemical resistance.

However, epoxy resins are inherently brittle due to their high cross-link density. To increase their toughness different modifiers such as rubber, thermoplastic and glass particles can be added, but they always limit the processability of the formulation [16-20]. Hyperbranched polymers (HBP) are a new kind of polymers used as modifiers of epoxy resins to increase their toughness without sacrificing the processing ability of the formulation due to their highly branched dendritic structure, which is a key point in coating applications [9-11, 21-23]. HBPs have several advantages as their low viscosity compared with their liner counterparts, the possibility of tailoring their core and branched structures and the functionalization of the end groups so that they can be made compatible with the surrounding matrix $[24,25]$. These modifiers can also reduce the shrinkage of the resin during the curing process [26] and the generation of internal stress [9]. HBPs can also maintain the glass transition of the epoxy resin [9], but in some cases a significant reduction was observed [24]. In previous works of our group, the influence of some HBPs in the thermal curing and the photocuring of diglycidyl ether of bisphenol A (DGEBA) has been studied [27-31]. Using HBP polyester partially blocked with benzoyl groups

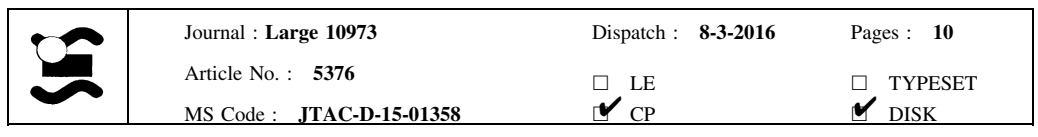


as epoxy modifier, a phase-separated morphology, with a part of the HBP segregate into particles, was obtained. The $\pi-\pi$ stacking interactions between phenyl groups and the different hydrophilic character of HBP core and terminals groups were the forces that drive the phase separation process. The existence of some hydroxyl terminal groups improved the compatibility with the epoxy matrix due to the formation of covalent linkages and, as a consequence, thermosetting materials with improved flexibility and toughness were obtained [30]. Hyperbranched poly (ethylene imine) polymers were used as reactive polymeric modifiers in epoxy thermosetting systems using a tertiary amine as anionic initiator. These HBPs were able to get incorporated into the network structure by condensation of amine and epoxy groups. The densely branched architecture of PEI and grafting between the condensed epoxyamine and polyether network reduced significantly the network mobility, but a positive effect in terms of impact resistance could be observed [31].

Taking all of these into account, in the present work three new hyperbranched poly(ethylene imine) polymers with different terminal groups (two of them with different amounts of $t$-butyl terminal groups and the other one with phenyl terminal groups) have been synthesized. Phenyl and $t$-butyl groups are introduced to block active amines of poly(ethyleneimine) structure and therefore reduce the extent of covalent linkage between the HBP and the epoxy matrix, with the purpose of promoting phase separation and enhancing impact strength [32]. The synthetic procedure to prepare the polymeric modifiers is quite easy and consists in reacting commercial poly(ethylene imine) with the corresponding isocyanate in acetonitrile solution at room temperature. The obtained HBPs have been characterized by ${ }^{1} \mathrm{H}-\mathrm{NMR}$ (proton nuclear magnetic resonance) and Fourier transform infrared spectroscopy (FTIR). The influence of these new HBPs on the thermal curing of an epoxy-anhydride system has been studied. The kinetics of the thermal curing has been analyzed using isoconversional methods. The effect of these HBPs over the storage modulus, and the thermal degradation has also been studied.

\section{Experimental}

\section{Materials}

Diglycidyl ether of bisphenol A (DGEBA) with an epoxy equivalent of $187 \mathrm{~g} \mathrm{ee}^{-1}$ (EPIKOTE 828, Herion Specialty Chemicals B. V.) was dried in vacuum before use. Hexahydro-4-methylphthalic anhydride of $186.19 \mathrm{~g} \mathrm{eq}^{-1}$ (Aldrich) was used as hardener, and $N, N$-dimethylbenzylamine (DMBA) (Aldrich) was used as catalyst.
Poly(ethylene imine) (PEI) (Lupasol ${ }^{\circledR} \mathrm{FG}, 800 \mathrm{~g} / \mathrm{mol}$, BASF) (see Fig. 1a) was donated by the producer and used after drying under vacuum. From the molar mass of the polymer and of the repeating unit, an average degree of polymerization of 18.6 was calculated. According to the data sheet, the relationship $\left(\mathrm{NH}_{2} / \mathrm{NH} / \mathrm{N}\right)$ was $(1 / 0.82 / 0.53)$ and thus by calculations the equivalent number of primary, secondary and tertiary amines resulted to be 0.010 , 0.00837 , and $0.0053 \mathrm{eq} \mathrm{g}^{-1}$. Phenyl isocyanate and tert-AQ1 23 butyl isocyanate were purchased from Sigma-Aldrich and 124 used as received. Acetonitrile (ACN) was dried and dis- 125 tilled under $\mathrm{CaH}_{2}$ before used.

Modification of poly(ethylene imine) with phenyl isocyanate (PEI-PhNCO) (Scheme 1)

The modification of PEI with the selected isocyanate was performed according to a general reported procedure [33]. The synthesis of PEI-PhNCO was performed by solving $3.24 \mathrm{~g}$ (58.3 meq of $-\mathrm{NH})$ of PEI in $20 \mathrm{~mL}$ of acetonitrile in a three-necked flask magnetically stirred. The solution was brought to $0{ }^{\circ} \mathrm{C}$, and phenyl isocyanate $(6.95 \mathrm{~g}$, $58.3 \mathrm{mmol}$ ) was added drop-wise. Once the addition was finished, the mixture was left at room temperature overnight. The solvent was eliminated in the rotary evaporator, and the white powder obtained was dried in vacuum overnight. In Scheme 1, the reaction between PEI and phenyl isocyanate is shown.

PEI-PhNCO ${ }^{1} \mathrm{H}-\mathrm{NMR}\left(400 \mathrm{MHz}, \mathrm{CDCl}_{3}\right), \delta(\mathrm{ppm})$ : 7.7-6.7 $\left(\mathbf{H}_{\mathbf{a r}}, \mathrm{i}-1\right), 3.5-1.6\left(-\mathrm{CH}_{2}-\mathrm{NHCO}-, \mathrm{g},-\mathrm{CH}_{2}-\right.$ $\mathrm{N}\left(\mathrm{CH}_{2}\right) \mathrm{CO}-$, f), and PEI (-NH-C $\mathrm{C}_{2} \mathrm{CH}_{2}-\mathrm{NH}-$, e) (see Fig. 1b).

\section{Modification of poly(ethylene imine) with $t$-butyl isocyanate (PEI-t-butylNCO)}

131

132

133

134

135

136

137

138

139

140

141

142

143

144

145

146

The synthetic procedure was similar to that used in the previous description, but two different quantities of $t$-butyl isocyanate were employed: $5.78 \mathrm{~g}(58.3 \mathrm{mmol})$ to reach a $100 \%$ of modification (from now on PEI-BuNCO100) and $4.33 \mathrm{~g}(43.68 \mathrm{mmol})$ to reach a modification degree of $75 \%$ (from now on PEI-BuNCO75).

PEI-BuNCO100 ${ }^{1} \mathrm{H}-\mathrm{NMR}\left(400 \mathrm{MHz}, \mathrm{CDCl}_{3}\right), \delta$ (ppm): 3.5-1.6 (- $\mathrm{CH}_{2}-\mathrm{NHCO}-$, g, $-\mathrm{CH}_{2}-\mathrm{N}\left(\mathrm{CH}_{2}\right) \mathrm{CO}-$, f) and PEI (-NH-CH $\left.\mathrm{CH}_{2}-\mathrm{NH}-, \mathrm{c}-\mathrm{e}\right)$ and $1.3\left(\mathrm{CH}_{3}\right.$ of $t$-butyl groups) (see Fig. 1c).

Average molar mass and thermal data of all the modified HBPs obtained are collected in Table 1 .

\section{Preparation of curing formulations}

First, the desired quantities of DGEBA and solid HBP were 160 mixed, heated using a hot air blower, and vigorously

$\begin{array}{lll}\text { Journal : Large 10973 } & \text { Dispatch : 8-3-2016 } & \text { Pages : 10 } \\ \text { Article No. : } \mathbf{5 3 7 6} & \square \text { LE } & \square \text { TYPESET } \\ \text { MS Code : JTAC-D-15-01358 } & \boldsymbol{\sim}_{\mathrm{CP}} & \boldsymbol{\sim}_{\text {DISK }}\end{array}$


(a)

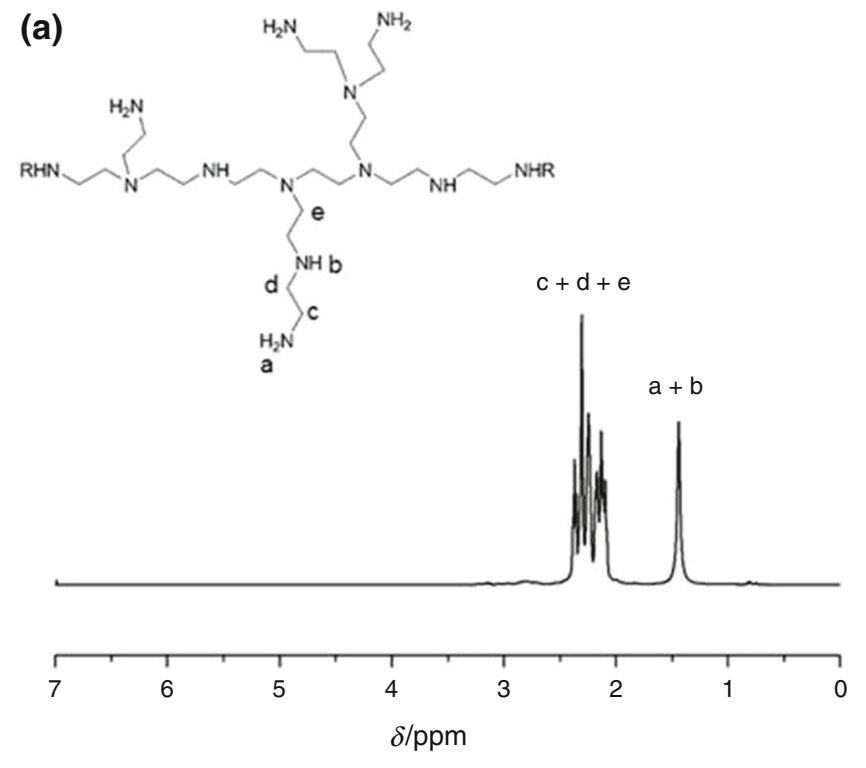

(b)
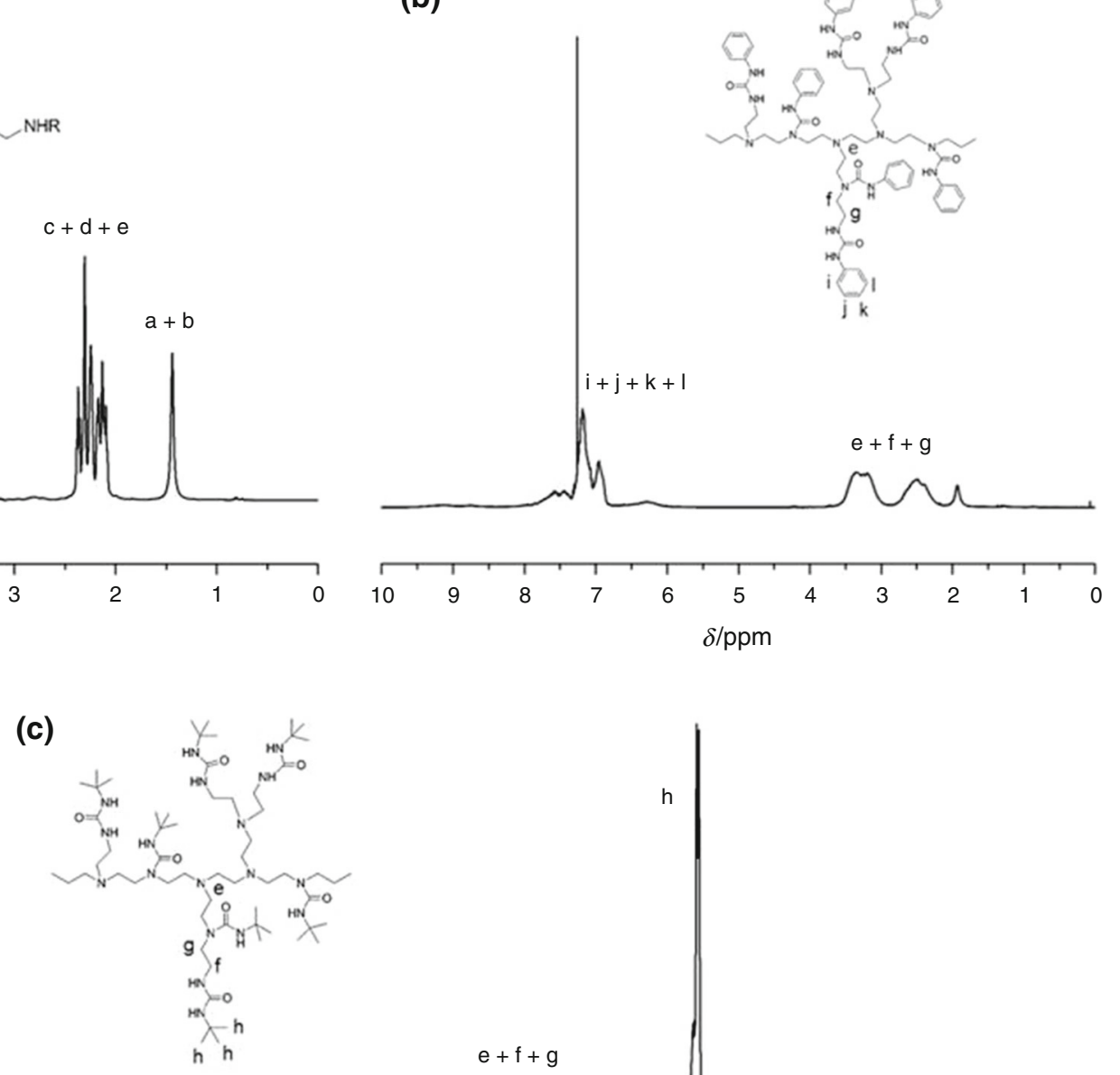

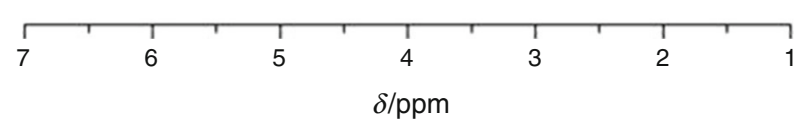

Fig. $1{ }^{1} \mathrm{H}$-NMR spectra of PEI (a), PEI-PhNCO (b), and PEI-BuNCO100 (c) in $\mathrm{CDCl}_{3}$
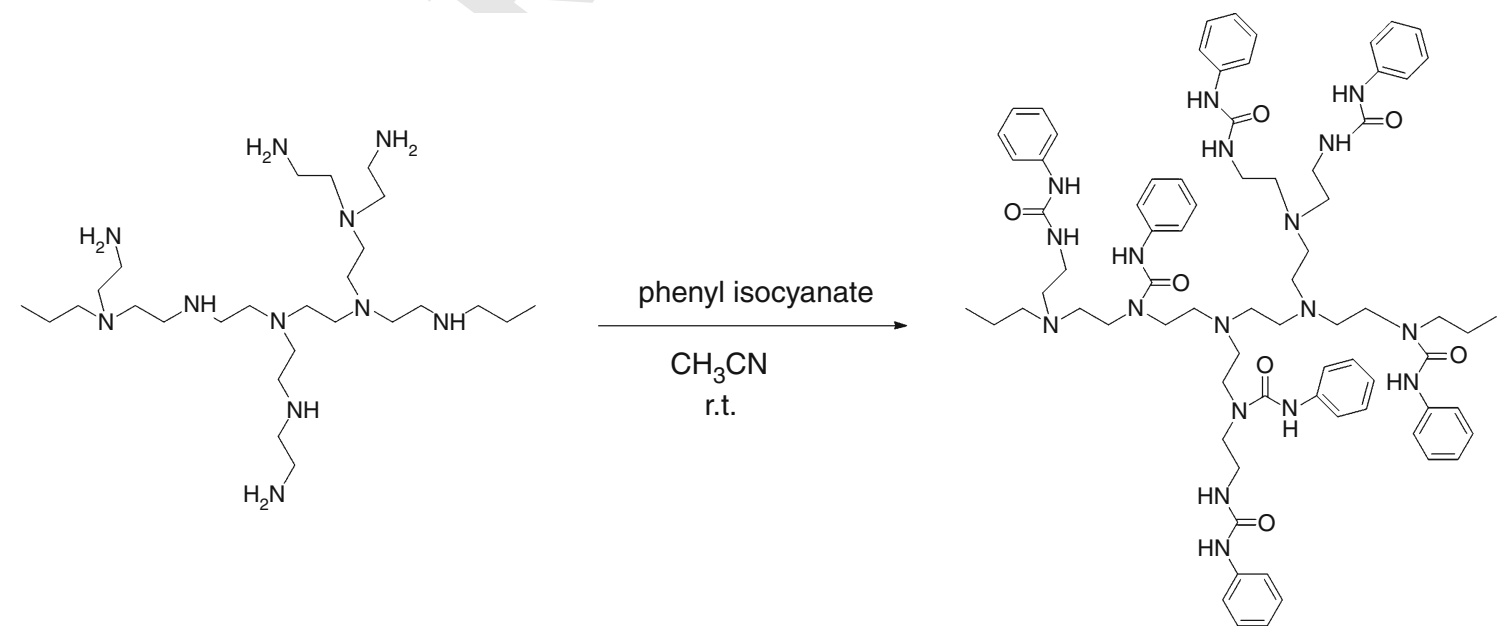

Scheme 1 Modification of PEI with phenyl isocyanate to obtain PEI-PhNCO

\begin{tabular}{|c|c|c|c|c|}
\hline & Journal : Large 10973 & Dispatch & 8-3-2016 & Pages : $\mathbf{1 0}$ \\
\hline & $\begin{array}{l}\text { Article No. : } \mathbf{5 3 7 6} \\
\text { MS Code : } \quad \text { JTAC-D-15-01358 }\end{array}$ & $\begin{array}{l}\boldsymbol{V}_{\mathrm{CP}}^{\mathrm{LE}} \\
\mathrm{V}\end{array}$ & & $\begin{array}{ll}\square & \text { TYPESET } \\
\boldsymbol{V} & \text { DISK }\end{array}$ \\
\hline
\end{tabular}


Table 1 Characteristics of the modified HBPs synthesized

\begin{tabular}{lcll}
\hline Modifier & $\mathrm{DA}^{\mathrm{a}} / \%$ & $M_{\mathrm{n}}^{\mathrm{a}} / \mathrm{g} \mathrm{mol}^{-1}$ & $T_{5 \%}^{\mathrm{b}} /{ }^{\circ} \mathrm{C}$ \\
\hline PEI-BuNCO100 & 99 & 2174 & 204 \\
PEI-BuNCO75 & 74 & 1827 & 196 \\
PEI-PhNCO & 100 & 2468 & 238 \\
\hline
\end{tabular}

${ }^{a}$ Determined by ${ }^{1} \mathrm{H}-\mathrm{NMR}$

b Temperature of the $5 \%$ of mass loss

stirred. When this mixture reached room temperature, the anhydride (in a stoichiometric proportion with respect to DGEBA) and $1 \mathrm{phr}$ of the tertiary amine (one part per hundred of DGEBA and anhydride mixture) were added. Immediately after, the mixture obtained was introduced in a vacuum oven to completely remove bubbles of air. The proportion of the different HBPs used was 5 and $10 \%$. The prepared mixtures were kept at $-18{ }^{\circ} \mathrm{C}$ to prevent polymerization and used subsequently in the corresponding studies.

\section{Nuclear magnetic resonance of hydrogen}

${ }^{1} \mathrm{H}-\mathrm{NMR}$ measurements were carried out at $400 \mathrm{MHz}$ and in a Varian Gemini 400 spectrometer. $\mathrm{CDCl}_{3}$ was used as the solvent. For internal calibration, the middle solvent signal corresponding to $\mathrm{CDCl}_{3}$ was taken as $\delta\left({ }^{1} \mathrm{H}\right)=$ $7.26 \mathrm{ppm}$.

\section{Fourier transform infrared spectroscopy}

FTIR spectrometer FTIR-680PLUS from Jasco with a resolution of $4 \mathrm{~cm}^{-1}$ in the absorbance mode was used to confirm that the reaction of isocyanate with polyethyleneimine was completed. This device was equipped with an attenuated-total-reflection accessory with thermal control and a diamond crystal (Golden Gate heated single reflection diamond ATR, Specac Teknokroma).

\section{Differential scanning calorimetry}

The kinetics of the thermal curing were evaluated by DSC analysis (differential scanning calorimetry, Mettler DSC$822 \mathrm{e}$ calorimeter) from 0 to $300{ }^{\circ} \mathrm{C}$ at different heating rates $\left(2.5,5,7.5,10\right.$, and $\left.15{ }^{\circ} \mathrm{C} \mathrm{min}{ }^{-1}\right)$. The samples cured at $10{ }^{\circ} \mathrm{C} \mathrm{min}{ }^{-1}$ were used to determine the maximum glass transition temperature reached in a second scan from 0 to $300{ }^{\circ} \mathrm{C}$ at $10{ }^{\circ} \mathrm{C} \mathrm{min}^{-1}$.

\section{Dynamic mechanical analysis}

To prepare the specimens, the mixtures were completely cured in a rectangular mold, first at $100{ }^{\circ} \mathrm{C}$ for $2 \mathrm{~h}$ and then at $150{ }^{\circ} \mathrm{C}$ for $1 \mathrm{~h}$. Before curing, PEI-PhNCO was completely solubilized in the epoxy matrix, but PEI-BuNCO75 and PEI-BuNCO100 were not. After the heating and curing, all the modifiers are apparently solubilized in the epoxy matrix. The materials obtained were homogeneous and transparent to the naked eye. The dimensions of the specimens were $20 \times 11 \times 2 \mathrm{~mm}^{3}$, approximately. The samples were tested in a DMA (dynamic mechanical analysis, TA instruments Q800) from -120 to $220{ }^{\circ} \mathrm{C}$ at $3{ }^{\circ} \mathrm{C} \mathrm{min}{ }^{-1}$ using the 3-point bending mode, with an amplitude of $10 \mu \mathrm{m}$ and a frequency of $1 \mathrm{~Hz}$.

\section{Thermogravimetric analysis}

Small specimens $(8-10 \mathrm{mg})$ of the completely cured samples (following the procedure described above for the DMA analysis) were analyzed from 30 to $800{ }^{\circ} \mathrm{C}$ at $10{ }^{\circ} \mathrm{C} \mathrm{min}^{-1}$ in a thermobalance (Mettler TGA/DSC1) in nitrogen atmosphere $\left(60 \mathrm{~cm}^{3} \mathrm{~min}^{-1}\right)$ to study the degradation process. Only the neat epoxy resin and the ones with $10 \%$ of the different HBPs were analyzed.

\section{Theory}

In the thermal curing studied, the degree of conversion is defined as:

$\alpha=\frac{\Delta h_{T}}{\Delta h_{\mathrm{dyn}}}$

where $\Delta h_{T}$ is the heat released up to a temperature $T$ and $\Delta h_{\mathrm{dyn}}$ is the total reaction heat released during the curing. The kinetics of this curing has been analyzed by means of an integral isoconversional method, using the KissingerAkahira-Sunose equation [34]:

$\ln \left(\frac{\beta}{T_{\alpha}^{2}}\right)=\ln \left(\frac{A_{\alpha} R}{g(\alpha) E_{\alpha}}\right)-\frac{E_{\alpha}}{R T_{\alpha}}$

where is the heating rate, $R$ is the gas constant and at a determined value of degree of conversion, $T_{\alpha}$ is the temperature attained, $A_{\alpha}$ is the frequency factor, $E_{\alpha}$ is the activation energy and $g(\alpha)$ is the following integral obtained from a function of the degree of conversion $f(\alpha)$ :

$g(\alpha)=\int_{0}^{\alpha} \frac{\mathrm{d} \alpha}{f(\alpha)}$

The activation energy at a given conversion can be obtained from the slope of the representation of $\ln \left(\beta / T_{\alpha}^{2}\right)$ versus the reciprocal of the temperature [see Eq. (2)]. Providing the kinetic model is known; the frequency factor can also be determined from the intercept at the origin.
208 
This analysis can be repeated at different degrees of conversion throughout the curing process.

\section{Results and discussion}

\section{Characterization of the obtained HBPs}

Commercially available hyperbranched poly(ethylene imine) (PEI, Lupasol ${ }^{\circledR}$ FG) contains primary, secondary, and tertiary amine functional groups. From the degree of polymerization of PEI and the molar ratio of primary, secondary, and tertiary amines, we calculated the average number of active groups per molecule, $\mathrm{NH}$ and $\mathrm{NH}_{2}$, which resulted to be 6.4 secondary amines and 7.9 primary amines in average per molecule. From this number and the desired degree of modification, the quantity of phenyl and $t$-butyl isocyanates was calculated, taking into account that primary and secondary amines react with an only isocyanate group to form the corresponding urea. The reaction was performed by reacting the isocyanates with the PEI at low temperature using $\mathrm{ACN}$ as solvent (see Scheme 1).

By FTIR analysis, we could confirm that the desired modification was achieved due to the complete disappearance of the isocyanate band at $2271 \mathrm{~cm}^{-1}$ and the new urea groups formed that gives absorptions at $3321 \mathrm{~cm}^{-1}(\mathrm{~N}-\mathrm{H}$ st) and at $1623 \mathrm{~cm}^{-1}(\mathrm{C}=\mathrm{O} \mathrm{st})$.

To evaluate the real degree of modification, ${ }^{1} \mathrm{H}-\mathrm{NMR}$ spectra were registered (Fig. 1b, c). In the PEI-PhNCO spectrum, it can be observed the aromatic protons introduced in the 6.8-7.8 ppm (i, j, k, l) and the total absence of $\mathrm{NH}$ protons. In the case of PEI-BuNCO100, the signal (h) due to the methyl protons of the $t$-butyl groups allows the calculation of the degree of modification. The signals corresponding to the protons of the PEI structure shift because of the transformation of amines into urea groups.

The complete absence of amine protons $(\mathrm{a}+\mathrm{b}$ signals) in the spectrum of PEI-PhNCO indicates that a $100 \%$ of modification was reached. For the PEI-BuNCO polymers, the degree of modification was calculated by ${ }^{1} \mathrm{H}-\mathrm{NMR}$, following a previously reported method [35]. From the integration of the signals coming from the methyl groups and the PEI structure, we determined the ratio of urea formed by amine moiety according the following equation:

$x=\frac{I(\mathrm{~h}) / 9}{I(\mathrm{c}+\mathrm{d}+\mathrm{e}+\mathrm{f}+\mathrm{g}) / 4}$

where $I(\mathrm{~h})$ is the integration of methyl protons of butyl groups and $I(\mathrm{c}+\mathrm{d}+\mathrm{e}+\mathrm{f}+\mathrm{g})$ is the total integration of the protons coming from the PEI structure. From $x$ and the values of the primary amine end groups $(T)$, secondary amine linear units $(L)$, and tertiary amine branched units
$(D)$, it is possible to calculate the degree of amidation (DA) by using the following equation:

$\mathrm{DA}=\frac{x(L+T+D)}{L+T}$

A complete and $74 \%$ of modification were achieved in PEI-BuNCO HBPs. Primary amines are mainly located in the periphery, whereas secondary amines are in the middle of the spheroid-like structure. Because of the steric hindrance of the secondary amines and the higher nucleophilicity of primary amines, the latter should be much more reactive than the secondary ones and then most unreacted amines in PEI-BuNCO75 should be secondary, and therefore less active on further reaction in epoxy curing. In Table 1, the degree of modification achieved and the average molar mass calculated are collected. The initial decomposition temperature $\left(T_{5 \%}\right)$ was evaluated to confirm that during the curing process the PEI modifiers were enough stable to be cured without breakage of urea groups.

\section{Thermal curing}

Figures 2,3 , and 4 show the DSC scans at $10{ }^{\circ} \mathrm{C} \min ^{-1}$ or the epoxy system modified with different proportions of the HBPs used (in the insets, degree of conversion versus temperature). PEI-BuNCO100 (Fig. 2) hardly modifies the thermal curing, but PEI-BuNCO75 (Fig. 3) and PEI$\mathrm{PhNCO}$ (Fig. 4) accelerate and decelerate the thermal curing, respectively. In PEI-BuNCO75, there are some remaining amine groups that facilitate the opening of the epoxy ring increasing the reaction rate. PEI-PhNCO is the only modifier completely solubilized in the epoxy resin before the beginning of the thermal curing and it has a dilution effect on the reaction rate. Moreover, the high molar mass of PEI-PhNCO and the rigidity of phenyl groups hinder the mobility of the reactive species, decelerating the curing specially at lower temperatures [36].

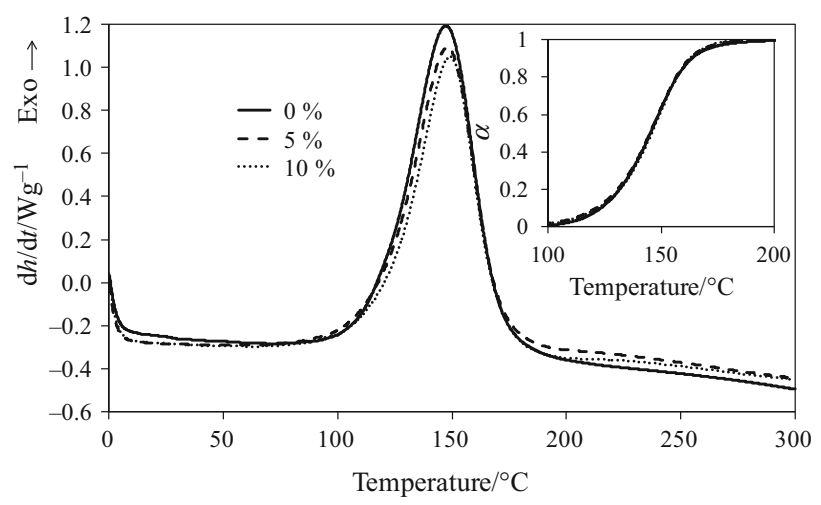

Fig. 2 Heat flow of thermal curing of the epoxy resin with different proportions of PEI-BuNCO100 at $10{ }^{\circ} \mathrm{C} \mathrm{min}-1$. In the inset, degree of conversion versus temperature

\begin{tabular}{|l|lll|}
\hline Journal : Large 10973 & Dispatch : 8-3-2016 & Pages : 10 \\
Article No. : $\mathbf{5 3 7 6}$ & $\square$ LE & $\square$ TYPESET \\
MS Code : JTAC-D-15-01358 & $\checkmark$ CP & $\checkmark$ DISK \\
\hline
\end{tabular}




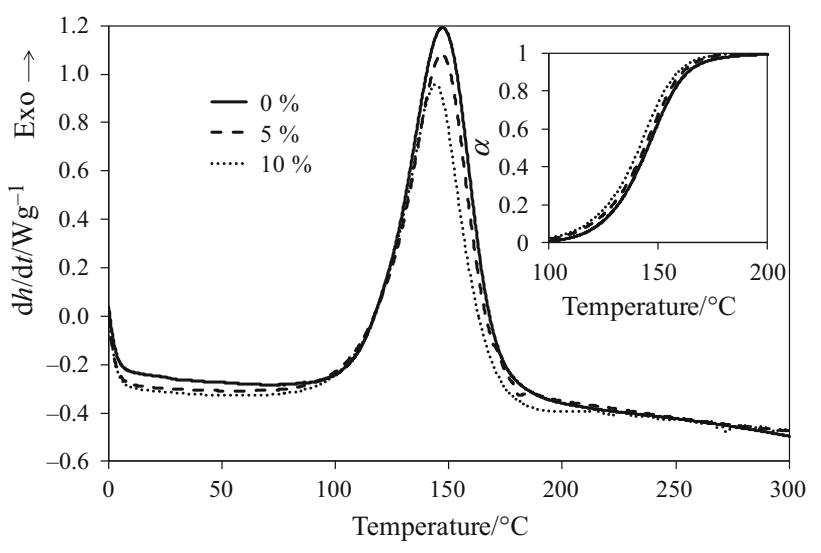

Fig. 3 Heat flow of thermal curing of the epoxy resin with different proportions of PEI-BuNCO75 at $10{ }^{\circ} \mathrm{C} \mathrm{min}{ }^{-1}$. In the inset, degree of conversion versus temperature

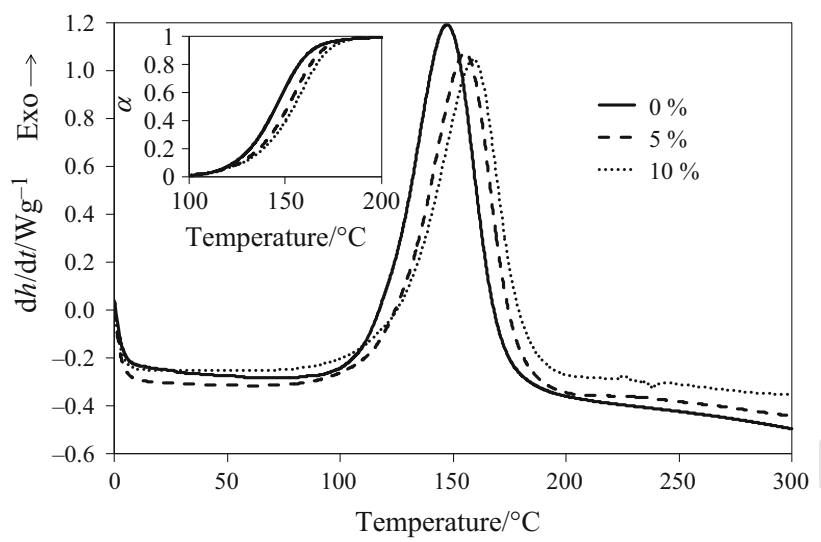

Fig. 4 Heat flow of thermal curing of the epoxy resin with different proportions of PEI-PhNCO at $10{ }^{\circ} \mathrm{C} \mathrm{min}-1$. In the inset, degree of conversion versus temperature
To analyze the kinetics of the process, an integral isoconversional method is used as it has been commented in the theoretical part. To find the frequency factor, modelfitting method and the Šesták-Berggren equation $\left(f(\alpha)=\alpha^{m}(1-\alpha)^{n}\right)$ [34] have been used with $m+n=2$ [37]. With this condition, the following expression for $g(\alpha)$ is obtained:

$g(\alpha)=\frac{1}{1-m}\left(\frac{\alpha}{1-\alpha}\right)^{1-m}$

This kinetic model has been selected since that the curing of epoxy-anhydride has been satisfactorily modeled in previous works [37-39]. As it can be seen in Table 2, the values of the parameters $m$ and $n$ are similar for the studied systems, an indication of the fact that the curing mechanism is not significantly affected by the presence of the star HBP modifier. Only the autocatalytic parameter $m$ slightly decreases when a $10 \%$ of PEI-PhNCO is added, probably due to the restrictions imposed by the modifier to the mobility of the reactive species. Table 3 shows the values of the activation energy and the frequency factor for all the studied systems obtained using Eq. (2) for some degrees of conversion. The values of the activation energy and the frequency factor are very similar for all the studied systems at the middle stage of the process. At the beginning, these parameters decrease on increasing the proportion of modifier and at the end, they increase with the modifier proportion, but these differences are small and they are not significant. This can be explained by uncertainties in the determination of the baseline and in consequence of the measurement of the reaction heat at the beginning and the end of the curing process. In many reactions, due to the compensation effect between the activation energy and the frequency factor [40], the activation energy does not reflect exactly the reaction rate and it is better to discuss the rate constants.

In Table 4, the values of the rate constant at $150{ }^{\circ} \mathrm{C}$ and $\alpha=0.5$ are indicated. These values have been found using the Arrhenius equation $(k=A \exp (-E / R T))$ and the values of the activation energy and the frequency factor of Table 3. These rate constants are in agreement with the results shown in Figs. 2 to 4: PEI-BuNCO100 hardly modifies the thermal curing (the rate constants are practically the same than that of the neat system), PEI-BuNCO75 accelerates it (the rate constant increases with the modifier proportion), and PEI-PhNCO decelerates it (the rate constant decreases increasing the modifier proportion). Equivalent results have been obtained in all range of conversions. The acceleration observed on adding PEIBuNCO75 could be attributed to the effect of unreacted $\mathrm{NH}$ groups in the modifier structure, which can react with epoxides and anhydrides because of their nucleophilic character. The deceleration observed can be explained on the basis of the dilution effect of reactive groups and the increase in viscosity on adding the PEI modifier.

In Table 4, the values of the ultimate glass transition temperature are also indicated. All the HBPs produce a decrease in the glass transition temperature, indicating that

Table 2 Values of the parameters $m$ and $n$ of the Šesták-Berggren equation, regression coefficient $(r)$ of the model-fitting method, and standard deviation (SD) for all the studied systems

\begin{tabular}{lllll}
\hline Modifier/\% & $m$ & $n$ & $r$ & SD \\
\hline $0 \%$ & 0.487 & 1.513 & 0.995 & 0.200 \\
$5 \%$ PEI-BuNCO100 & 0.478 & 1.522 & 0.990 & 0.247 \\
$10 \%$ PEI-BuNCO100 & 0.479 & 1.521 & 0.986 & 0.276 \\
$5 \%$ PEI-BuNCO75 & 0.495 & 1.505 & 0.990 & 0.256 \\
$10 \%$ PEI-BuNCO75 & 0.480 & 1.520 & 0.989 & 0.240 \\
$5 \%$ PEI-PhNCO & 0.491 & 1.509 & 0.988 & 0.243 \\
$10 \%$ PEI-PhNCO & 0.449 & 1.551 & 0.981 & 0.281 \\
\hline
\end{tabular}

\begin{tabular}{|l|lll|}
\hline Journal : Large 10973 & Dispatch : 8-3-2016 & Pages : $\mathbf{1 0}$ \\
Article No. : $\mathbf{5 3 7 6}$ & $\square$ LE & $\square$ TYPESET \\
& MS Code : JTAC-D-15-01358 & $\sim_{\mathrm{CP}}$ & $\checkmark$ DISK \\
\hline
\end{tabular}




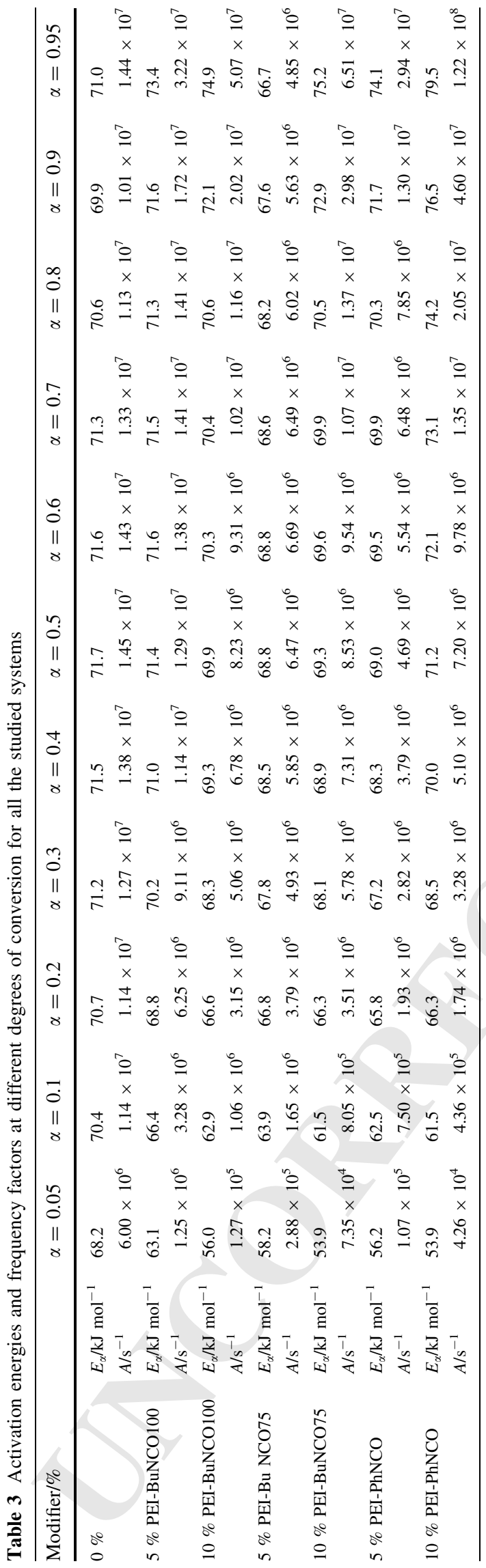

Table 4 Rate constants at $150{ }^{\circ} \mathrm{C}$ and $\alpha=0.5$, maximum glass transition $\left(T_{g \infty}\right)$ for all the studied systems and heating of cure (in kJ by equivalent epoxy)

\begin{tabular}{llll}
\hline Modifier/\% & $k_{150{ }^{\circ} \mathrm{C}} / \mathrm{s}^{-1}$ & $T_{g \infty} /{ }^{\circ} \mathrm{C}$ & $\Delta h / \mathrm{kJ} \mathrm{ee}^{-1}$ \\
\hline $0 \%$ & $2.04 \times 10^{-2}$ & 136 & 124 \\
$5 \%$ PEI-BuNCO100 & $1.98 \times 10^{-2}$ & 126 & 117 \\
$10 \%$ PEI-BuNCO100 & $1.91 \times 10^{-2}$ & 117 & 117 \\
$5 \%$ PEI-BuNCO75 & $2.09 \times 10^{-2}$ & 121 & 117 \\
$10 \%$ PEI-BuNCO75 & $2.36 \times 10^{-2}$ & 107 & 113 \\
$5 \%$ PEI-PhNCO & $1.43 \times 10^{-2}$ & 123 & 121 \\
$10 \%$ PEI-PhNCO & $1.18 \times 10^{-2}$ & 112 & 120 \\
\hline
\end{tabular}

they are solubilized in the epoxy matrix acting as plasticizers. The flexible PEI structure can also account for the lowering of $T_{g \infty}$. PEI-BuNCO75 is the modifier that decreases more this magnitude, but PEI-BuNCO100 is the modifier that decreases less it. It should be considered that the introduction of a modifier with reactive groups affects the stoichiometry of the formulation: since the epoxide and anhydride groups were maintained at stoichiometric proportions, the addition of PEI-BuNCO75 can leave some groups unreacted and a more open structure of the thermosetting network. Moreover, the covalent linkages between PEI-BuNCO75 and matrix can produce a more expanded structure with a lower amount of cross-link points per unit mass. As it can be seen in Table 4, the introduction of HBP slightly decreases the reaction heat, possibly because of the topological restrictions leading to incomplete curing and, in consequence, to a lower crosslinking density.

\section{Dynamic mechanical analysis}

Figures 5, 6 and 7 show the DMA experiments of the materials prepared. The presence of PEI-BuNCO75 and PEI-BuNCO100 in the material decreases the storage modulus $\left(E^{\prime}\right)$ before the glass transition, but the addition of PEI-PhNCO hardly changes it. After glass transition, all the modifiers decrease $E^{\prime}$, especially PEI-BuNCO75. As stated above, the chemical incorporation of PEI-BuNCO75 into the matrix reduces the cross-linking density. All modifiers decrease the glass transition temperature (temperature of the $\tan \delta$ peak). This result is in agreement with the trend observed in the values of the ultimate grass transition temperature obtained by DSC and agrees with the flexibilizing effect exerted by the modifiers on the matrix.

In the insets of these Figures, an enlargement of $\tan \delta$ at low temperatures is shown. These peaks correspond to the $\beta$ transition and increasing the modifier proportion, their temperature decreases, according to the fact that the HBP act as an internal plasticizer.

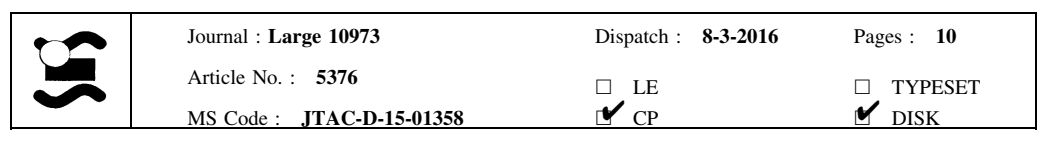




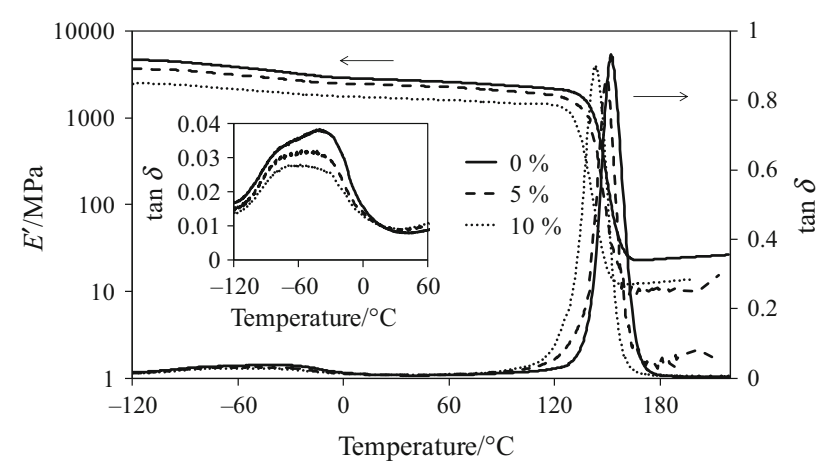

Fig. 5 Storage modulus $\left(E^{\prime}\right)$ and loss tangent $(\tan \delta$ ) of samples completely cured of the epoxy resin modified with different proportions of PEI-BuNCO100

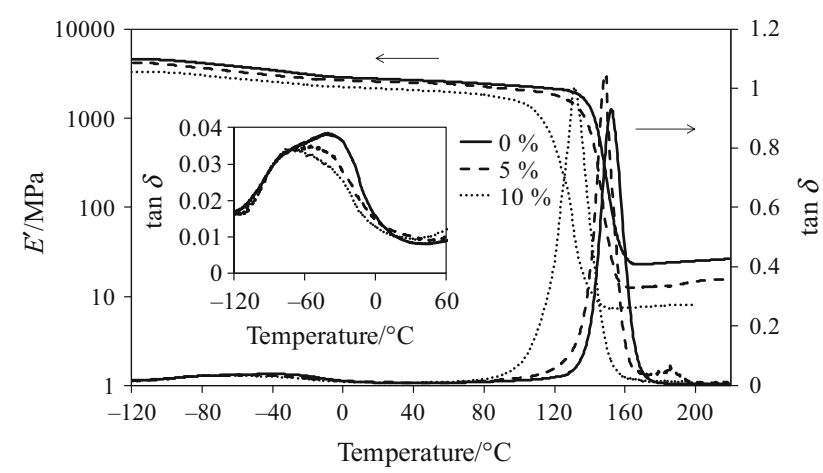

Fig. 6 Storage modulus $\left(E^{\prime}\right)$ and loss tangent $(\tan \delta$ ) of samples completely cured of the epoxy resin modified with different proportions of PEI-BuNCO75

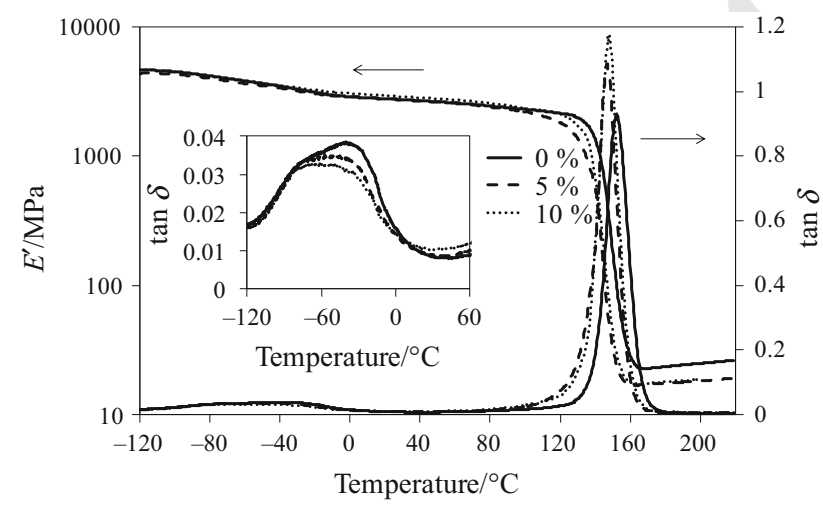

Fig. 7 Storage modulus $\left(E^{\prime}\right)$ and loss tangent $(\tan \delta)$ of samples completely cured of the epoxy resin modified with different proportions of PEI-PhNCO

In all the studied systems, there is only one glass tran-

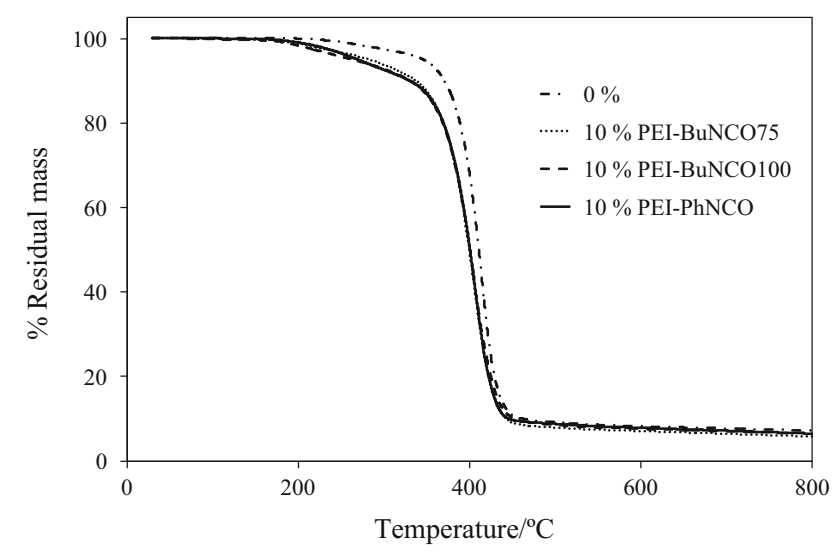

Fig. 8 Thermogravimetry at $10{ }^{\circ} \mathrm{C} \mathrm{min}^{-1}$ in nitrogen atmosphere of samples completely cured of the neat epoxy resin and of the same resin modified with $10 \%$ of the different modifiers

\section{Thermogravimetric analysis}

In Fig. 8, the thermal degradation process of the neat epoxy resin and the modified thermosets with $10 \%$ of the different HBPs is shown. The curves of this Figure are obtained subtracting a blank one to the corresponding to the samples. With the addition of the modifiers, the onset temperature of the degradation decreases, but this onset temperature is still greater than the curing temperature $\left(150{ }^{\circ} \mathrm{C}\right)$. This decrease is due to the decomposition of the urea groups of the modifier in a isocyanate group and the corresponding amine and of the poly(ethylene imine) at lower temperatures than the epoxy/anhydride matrix [41]. Tentatively, and according to the $T_{5 \%}$ values of the neat HBPs (Table 1), it can be considered that the thermal degradation of the cured materials starts by the decomposition and volatilization of the modifier, followed by the degradation of the epoxy/anhydride matrix at higher temperatures. In Fig. 8, it is shown that at the first part of the decomposition process, the decrease in mass is approximately $10 \%$, the same as the proportion of modifier in the formulation.

\section{Conclusions}

The reaction between poly(ethylene imine) and two different isocyanates is a practical method to obtain new hyperbranched polymers with blocked amino groups. Using ${ }^{1} \mathrm{H}-\mathrm{NMR}$, their structures have been elucidated.

The kinetics of curing has been correctly established using an integral isoconversional procedure and a modelfitting method and well fitted using an autocatalytic model. The addition of these novel HBPs synthesized to epoxy/ anhydride systems, in the presence of a tertiary amine as

\begin{tabular}{|l|lll|}
\hline & Journal : Large 10973 & Dispatch : 8-3-2016 & Pages : 10 \\
Article No. : 5376 & $\square$ LE & $\square$ \\
MS Code : JTAC-D-15-01358 & $\checkmark_{\text {CP }}^{\text {TYPESET }}$ \\
\hline
\end{tabular}


catalyst, barely modified the curing rate, which is controlled primarily by the mobility and concentration of the reactive species.

The addition of modified PEIs with phenyl and $t$-butyl terminal groups to epoxy/anhydride formulations allows obtaining thermosets with improved flexibility, due to the plasticizing influence of HBPs, with a slight reduction in glass transition temperature and cross-linking density and without affecting negatively processability. The final properties of the material obtained depend on the amount and type of modifier used.

Acknowledgements The authors would like to thank MINECO (Ministerio de Economía y Competividad) and FEDER (Fondo Europeo de Desarrollo Regional) (MAT2014-53706-C03-01 and MAT2014-53706-C03-02) and to the Comissionat per a Universitats i Recerca del DIUE de la Generalitat de Catalunya (2014-SGR-67).

\section{References}

1. Riew CK, Siebert AR, Smith RW, Fernando M, Kinloch AJ. Toughened epoxy resins: performed particles as tougheners for adhesives and matrices. In: Riew CK, Kinloch AJ, editors. Toughened plastics II novel approaches in science and engineering. Advances in chemical series, vol. 252. Washington: American Chemical Society; 1996. p. 33-44.

2. Saiki N, Yamazaki O, Ebe K. UV/heat dual-curable adhesive tapes for fabricating stacked packages of semiconductors. J Appl Polym Sci. 2008;108:1178-83.

3. Kang B-U. Interfacial fracture behavior of epoxy adhesives for electronic components. J Korea Acad Ind Cooper Soc. 2011;12:1479-87.

4. May CA, Tanaka GY. Epoxy resins. In: May CA, editor. Chemistry and technology, chap 1. New York: Marcel Dekker; 1988.

5. Petrie EM. Epoxy adhesive formulations. New York: McGrawHill; 2006.

6. Pascault JP, Williams RJJ. Epoxy polymers: new materials and innovations. Weinheim: Wiley-VCH; 2010.

7. Kinloch AJ, Shaw SJ, Tod DA, Hunston DL. Deformation and fracture behavior of a rubber-toughened epoxy: 1. Microstructure and fracture studies. Polymer. 1983;24:1341-54.

8. Ho T-H, Wang C-S. Toughening of epoxy resins by modification with dispersed acrylate rubber for electronic packaging. J Appl Polym Sci. 1993;50:477-83.

9. Mezzenga R, Boogh L, Månson JAE. A review of dendritic hyperbranched polymer as modifiers in epoxy composites. Compos Sci Technol. 2001;61:787-95.

10. Guo QP, Habrard A, Park Y, Halley PJ, Simon GP. Phase separation, porous structure, and cure kinetics in aliphatic epoxy resin containing hyperbranched polyester. J Polym Sci B. 2006;44:889-99.

11. Ratna D, Varley R, Simon GP. Toughening of trifunctional epoxy using an epoxy-functionalized hyperbranched polymer. J Appl Polym Sci. 2003;89:2339-45.

12. He S, Shi K, Bai J, Zhang Z, Li L, Du Z, Zhang B. Studies on the properties of epoxy resins modified with chain-extended ureas. Polymer. 2001;42:9641-7.

13. Evans D, Canfer SJ. Radiation stable, low viscosity impregnating resin systems for cryogenic applications. Adv Cryog Eng. 2000;46:361-8.
14. Ueki T, Nishijima S, Izumi Y. Designing of epoxy resin systems for cryogenic use. Cryogenics. 2005;45:141-8.

15. Nishijima S, Honda Y, Okada T. Application of the positron annihilation method for evaluation of organic materials for cryogenic use. Cryogenics. 1995;35:779-81.

16. Wu SH. Phase structure and adhesion in polymer blends; a criterion for rubber technology. Polymer. 1985;26:1855-63.

17. Pearson RA, Yee AF. Toughening mechanisms in thermoplasticmodified epoxies: 1. Modification using poly(phenylene oxide). Polymer. 1993;34:3658-70.

18. Hedrick JL, Yilgor I, Jurek M, Hedrick JC, Wilkes GL, McGrath JE. Chemical modification of matrix resin networks with engineering thermoplastics: 1. Synthesis, morphology, physical behaviour and toughening mechanisms of poly(arylene ether sulphone) modified epoxy networks. Polymer. 1991;32:2020-32.

19. Wilkinson SP, Ward TC, McGrath JE. Effect of thermoplastic modifier variables on toughening a bismaleimide matrix resin for high-performance composite materials. Polymer. 1993;34:870-84.

20. Kunz SC, Sayre JA, Assink RA. Morphology and toughness characterization of epoxy resins modified with amine and carboxyl terminated rubbers. Polymer. 1982;23:1897-906.

21. Voit B. New developments in hyperbranched polymers. J Polym Sci A. 2000;38:2505-25.

22. Boogh L, Pettersson B, Månson JAE. Dendritic hyperbranchesd polymers as tougheners for epoxy resins. Polymer. 1999;40:2249-61.

23. Zhang D, Liang E, Li T, Chen S, Zhang J, Cheng X, Zhou J, Zhang A. The effect of molecular weight of hyperbranched epoxy resins with a silicone skeleton on performance. RSC Adv. 2013;3:9522-9.

24. Sörensen K, Pettersson BO, Boogh L, Månson JAE. Dendritic polyester macromolecule in thermosetting resin matrix. PCT Pat./ SE94/04440; 1994.

25. Zhang D, Jia D, Chen S. Kinetics of curing and thermal degradation of hyperbranched epoxy (HTDE)/diglycidyl ether of bisphenol-A epoxy hybrid resin. J Thermal Anal Calorim. 2009;98:819-24.

26. Zhang Y, Zhang D, Qin $\mathrm{C}, \mathrm{Xu}$ J. Physical and mechanical properties of dental nanocomposites composed of aliphatic epoxy resin and epoxidized aromatic hyperbranched polymers. Polym Compos. 2009;30:176-81.

27. Fernández-Francos X, Salla JM, Cadenato A, Morancho JM, Serra A, Mantecón A, Ramis X. A new strategy for controlling shrinkage of DGEBA resins cured by cationic copolymerization with hydroxyl-terminated hyperbranched polymers and ytterbium triflate as an initiator. J Appl Polym Sci. 2009;111:2822-9.

28. Morancho JM, Cadenato A, Ramis X, Fernández-Francos X, Salla JM. Thermal curing and photocuring of an epoxy resin modified with a hyperbranched polymer. Thermochim Acta. 2010;510:1-8

29. Morancho JM, Cadenato A, Ramis X, Fernández-Francos X, Flores M, Salla JM. Effect of a hyperbranched polymer over the thermal curing and the photocuring of an epoxy resin. J Thermal Anal Calorim. 2011;105:479-88.

30. Foix D, Fernández-Francos X, Salla JM, Serra A, Morancho JM, Ramis X. New thermosets obtained from bisphenol A diglycidyl ether and hydroxyl-ended hyperbranched polymers partially blocked with benzoyl and trimethylsilyl groups. Polym Int. 2011;60:389-97.

31. Fernández-Francos X, Santiago D, Ferrando F, Ramis X, Salla JM, Serra A, Sangermano M. Network structure and thermomechanical properties of hybrid DGEBA networks cured with 1-methylimidazole and hyperbranched poly(ethyleneimine)s. J Polym Sci B Polym Phys. 2012;50:1489-503.

32. Flores M, Fernández-Francos X, Ferrando F, Ramis X, Serra A. Efficient impact resistance improvement of epoxy/anhydride 
thermosets by adding hyperbranched polyesters partially modified with undecenoyl chains. Polymer. 2012;53:5232-41.

33. Vandenabeele-Trambouze O, Mion L, Garrelly L, Commeyras A. Reactivity of organic isocyanates with nucleophilic compounds: amines; alcohols thiols; oximes; and phenols in dilute organic solutions. Adv Envir Res. 2001;6:45-55.

34. Vyazovkin S, Burnham AK, Criado JM, Pérez-Maqueda LA, Popescu C, Sbirrazzuoli N. ICTAC Kinetics Committee recommendations for performing kinetic computations on thermal analysis data. Thermochim Acta. 2011;520:1-19.

35. Liu H, Chen Y, Shen Z. Thermoresponsive hyperbranched polyethylenimines with isobutyramide functional groups. J Polym Sci A Polym Chem. 2007;45:1177-84.

36. Santiago D, Fernández-Francos X, Ramis X, Salla JM, Sangermano M. Comparative curing kinetics and thermal-mechanical properties of DGEBA thermosets cured with a hyperbranched poly(ethyleneimine) and an aliphatic triamine. Thermochim Acta. 2011;526:9-21.
37. Flores M, Fernández-Francos X, Ramis X, Serra A. Novel epoxyanhydride thermosets modified with a hyperbranched polyester as toughness enhancer. Thermochim Acta. 2012;544:17-26.

38. Montserrat S, Andreu G, Cortes P, Calventus Y, Colomer P, Hutchinson JM, Malek J. Addition of a reactive diluent to a catalyzed epoxy-anhydride system. I. Influence on the cure kinetics. J Appl Polym Sci. 1996;61:1663-74.

39. Xu J, Holst M, Wenzel M, Alig I. Calorimetric studies on an anhydride cured epoxy resin from diglycidyl ether of bisphenol-A and diglycidyl ether of poly(propylene glycol). I. Onset of diffusion control during isothermal polymerization. J Polym Sci B Polym Phys. 2008;46:2155-65.

40. Vyazovkin S, Wight CA. Kinetics in solids. Annu Rev Phys Chem. 1997;48:125-49.

41. Schaber PM, Colson J, Higgins S, Thielen D, Anspach B, Brauer J. Thermal decomposition (pyrolysis) of urea in an open reaction vessel. Thermochim Acta. 2004;424:131-42.

\begin{tabular}{|l|lll|}
\hline Journal : Large 10973 & Dispatch : 8-3-2016 & Pages : 10 \\
Article No. : $\mathbf{5 3 7 6}$ & $\square$ LE & $\square$ TYPESET \\
& MS Code : JTAC-D-15-01358 & $\sim_{\text {CP }}$ & $\checkmark$ DISK \\
\hline
\end{tabular}


Journal : 10973

Article : 5376

\section{Author Query Form}

\section{算 Springer}

the language of science

\section{Please ensure you fill out your response to the queries raised below and return this form along with your corrections}

\section{Dear Author}

During the process of typesetting your article, the following queries have arisen. Please check your typeset proof carefully against the queries listed below and mark the necessary changes either directly on the proof/online grid or in the 'Author's response' area provided below

\begin{tabular}{|l|l|c|}
\hline Query & Details Required & Author's Response \\
\hline AQ1 & $\begin{array}{l}\text { Figure 1 (low res) is poor in quality as it looks fuzzy. Please supply a high-resolution version of the said } \\
\text { figure preferably in .tiff or .jpeg format with 300 dpi resolution. }\end{array}$ & \\
\hline
\end{tabular}

